\title{
Comparative Study of Atorvastatin and Rosuvastatin on Serum Lipid Profile in Cardiac Patients with Diabetes
}

\author{
Authors \\ Dr Ashish Sharma, Dr Manish Pokra, Dr Ajay Kumar Bhargava
}

\begin{abstract}
Hyperlipidemia is a disorder of lipoprotein metabolism, which includes a number of abnormalities such as hypercholesterolemia and hypertriglyceridemia. Recently World Health Organization (WHO) has declared that by 2020, 60\% of cardiovascular cases will be of Indian origin. Treatment of hyperlipidemia with statins has become an integral part of management of vascular diseases. Indications of statins have been greatly extended over the last 5 years subsequent to the publication of many multicenter prospective trials. There are multiple statins available in the Indian market like atorvastatin, simvastatin, pravastatin, pitavastatin, fluvastatin, cerivastatin and rosuvastatin. Hypolipidemic effect of statins is due to inhibition of hydroxymethylglutaryl-CoA reductase (HMG-CoA) and decrease in $L D L-C$ is due to up regulation of $L D L$ receptor activity The objective of this study is to evaluate and compare the efficacy and safety of Rosuvastatin $20 \mathrm{mg}$ and Atorvastation $20 \mathrm{mg}$ among cardiac patients with hyperlipidemia in diabetics and non diabetics.
\end{abstract}

\section{Introduction}

Statins are the first line therapy for lowering lipid levels (Kumar T and Kapoor A 2005). Statins have become the leading prescription drug (Ravi GR et al 2004, Wierzbicki AS et al 1999). Most of the trials compared the fixed-dose regimens of more intensive statin therapy with less intensive statin therapy (Fleg JL et al 2008). Recent studies in patients with stable coronary disease showed greater reduction in C-reactive protein (CRP) with higher dose than with lower dose of statins (Josan $\mathrm{K}$ et al 2008). However, various studies suggest that efficacy and safety of various statins in hyperlipidemia differs considerably (Anderson KM et al. 1991). It is difficult for the medical practitioners to select suitable statins for their patients (Kinlay S et al. 2003).

Dyslipidemia is the commonest cause of the blood vessel diseases and their incidence has been rising all over the world thereby increasing the morbidity and mortality due to cardiovascular diseases. Dyslipidemia occurs due to disturbance in the lipid parameters like Total Cholesterol, LDL-C, VLDL, TGs and HDL-C (Brunzell JD et al. 2007, Talbert R L et al 2008).

Dyslipidemia is also one of the component of Metabolic syndrome along with other group of cardiovascular risk factors such as high blood pressure (BP), abdominal obesity, and insulin intolerance, whose concurrent appearance 
increases the risk of atherosclerotic cardiovascular disease (Brewer HB Jr. 2003).

Combined or mixed hyperlipidemia (CHL) is a lipid disorder characterized by increased lowdensity lipoprotein cholesterol (LDL-C), elevated triglycerides (TGs) and decreased high-density lipoprotein cholesterol (HDL-C) which is more common in patients with type 2 diabetes mellitus (Farnier M, Picard S 2001).

National cholesterol education program-Adult Treatment Panel-III (NCEP-ATP III) has set a goal to treat these dyslipidemic patients and which canbe achieved by proper treatment with lipid lowering drugs especially statins (National CEPATP III, 2002).

A number of lipid lowering drugs e.g. statins, fenofibrate, niacin, ezetamibe, bile sequestrants etc. are being used to treat this disorder (Talbert RL 2008).

Many studies are carried out on these drugs out of which few have been made in the people of North India especially in the Majhar region of Punjab because their socio-economic background and standard of living is quite different from the people of Western countries (Bhopal Raj et al. 1999).

Hypolipidemic effect of statins is due to inhibition of hydroxymethylglutaryl-CoA reductase (HMGCoA) and decrease in LDL-C is due to up regulation of LDL receptor activity (Ellen RL, Mc Pherson R 1998).

Outcome trials of statins have proved conclusively that these drugs decrease LDL-C levels, resulting in a significant reduction of cardiovascular events in many high-risk patients (Bakker-Arkema et al. RG 1996, Cannon CP et al. 2004). ${ }^{[15,16]}$

Rosuvastatin has been considered superior in achieving greater LDL-C level reductions as compared to atorvastatin, simvastatin, or pravastatin use (Mc Kenney JM et al. 2003).

Statins have also been reported to produce "pleiotropic" effects such as vasodilatation, antioxidant, plaque stabilization, antithrombotic and anti-inflammatory effects (Guerin $\mathrm{M}$ et al. 2000).
Statins or fibrates affect different aspects of lipoprotein metabolism. Hence, statin or fibrate monotherapy becomes difficult to modify the lipid profile of patients with combined hyperlipidemia according to the recent investigations of the American Diabetes Association (Haffner SM, 2002).

Combined therapy with statins and fibrates is more effective in controlling lipid profile in patients with mixed hyperlipidemia (CHL) (Haffner SM 2002, Vega et al 2003, Fievet C, Staels B 2009, Athyros VG et al. 1997, Kiortisis DN et al 2000).

\section{Aims and Objectives}

The aims and objective of our study were as follows:

To compare efficacy of equivalent doses of Rosuvastatin and Atorvastatin lowering LDL- C levels.

Compare the safety and efficacy of Rosuvastatin and Atorvastatin in reducing cardiovascular events in patients with coronary artery disease and elevated lipid levels.

\section{Material and Methods}

Present study was randomize, parallel group, open-label study conducted at SRG hospital \& Jhalawar Medical College, Jhalawar, Rajasthan, India. Hundred hyperlipidemia patients each taking atorvastatin $20 \mathrm{mg}$ and rosuvastatin $20 \mathrm{mg}$ tablets were selected for the study after clinical and baseline investigations. The patients reviewed after $5^{\text {th }}$ week of statin therapy for lipid profile.

The present study was carried out in the Department of Biochemistry in collaboration with Department of Medicine, Jhalawar Medical College, Jhalawar.

\section{Nature of the study}

Open label, randomize, parallel group, comparative, prospective clinical Study.

\section{Source of patient}

The patients attending outpatient department (O.P.D.) of Medicine enrolled into the present study. 


\section{Study population}

A total of 100 subjects diagnosed with combined hyperlipidemia screened for the entry into the study and were randomly allocated into two groups of fifty each.

\section{Inclusion criteria}

Male patients (35-85 years) and female patients (35-85 years) having low density lipoprotein cholesterol (LDL-C) higher than $100 \mathrm{mg} / \mathrm{dl}$ and triglycerides (TG) more than $200 \mathrm{mg} / \mathrm{dL}$ will be included in the study. All patients with Hypertension, Diabetes mellitus, Obesity and coronary artery disease included in the study.

\section{Exclusion criteria}

Patients with Renal and hepatic failure, Pregnancy and lactation, Hypothyroidism, Malignancy, Myopathy, Patients undergoing bypass surgery and those with concurrent medications like warfarin, verapamil,

\section{Methodology}

The total hundred $(n=100)$ patients enrolled in the study and randomly allocated into two groups of fifty $(n=50)$ each, using a randomization chart.

Initial readings of plasma lipid levels like TC, TG, HDL, LDL and VLDL for both the groups were taken as baseline values before assigning the treatment.

Then, Group I received Tab.Atorvastatin $20 \mathrm{mg}$ and Group II received Tab. Rosuvastatin $20 \mathrm{mg}$. Both the groups received 1 tablet once a day at night for 5 weeks. Patients assessed after 5 weeks and their Serum Lipid profile was done.

\section{Biochemical Examination}

Collected $5 \mathrm{ml}$ blood in plane vial from subject and the serum is separated.

Following investigations were carried out:

Lipid Profile Determination of serum lipid profile:

Estimation of Serum Total Cholesterol: by kit reagents (supplied by ERBA Diagnostics) on Semi autoanalyzer.

Estimation of HDL Cholesterol: Estimation of serum HDL cholesterol will be carried out on semi automatic analyzer
Method: Burstein method (Burstein et al 1974).

Estimation of Triglycerides: The estimation of serum Triglycerides was carried out on semi automatic analyzer

Method: Modified Wako, McGowan and Fossati method. (Wako et al 1983).

\section{Estimation of Low Density Lipoprotein Cholesterol}

Serum LDL is calculated by Friedwald's equation LDL cholesterol $=$ Total Cholesterol $-(\mathrm{HDL}$ Cholesterol + VLDL Cholesterol)

LDL was estimated by direct method when TG values were $>400 \mathrm{mg} / \mathrm{dl}$

\section{Estimation of Very Low - Density Lipoprotein} Cholesterol.

VLDL Cholesterol is calculated by Friedwald's equation

The criteria for selection of the patients was that they must have a total serum cholesterol level $>200 \mathrm{mg} / \mathrm{dl}$, LDL Cholesterol level of > 130 $\mathrm{mg} / \mathrm{dl}$ and serum triglyceride level of $<350 \mathrm{mg} / \mathrm{dl}$ measured within first 24 hours after the onset of the acute coronary syndrome or upto six months earlier if no sample had been obtained during first 24 hours.

The patients were studied under two groups as follows:

\begin{tabular}{|l|c|c|}
\hline Groups & No. Of Patients & Drug With Dose \\
\hline A & 50 & ATORVASTATIN 20 mg \\
\hline B & 50 & ROSUVASTATIN 20mg \\
\hline
\end{tabular}

All patients were followed up after 5 weeks.

\section{Results \& Discussion}

The present study is conducted to make the best and most effective results and the 5 lipid parameters are evaluated statistically in this study to show the significant actions of therapies.

In order to describe the results, table 1 shows The mean age of subjects which received atorvastatin is 60.42 and the age of patients receiving rosuvastatin is 59.76 and there is no significant difference between the mean age of treatment groups. ( $p>0.05)$. it means patient have age matched in both treatment groups. 
There is equal ratio of gender for both treatment group and have no significant difference in gender receiving the treatment. $(\mathrm{p}>0.05)$

There is no significant difference in mean glucose level in both treatment groups. ( $p>0.05)$. the mean glucose level of atorvastatin group is 258.84 and in rosuvastatin group is 275.3 .

There is no significant difference in mean serum cholesterol level in both treatment groups $(p>0.05)$. The mean serum cholesterol level of atorvastatin group is 258.84 and in rosuvastatin group is 247.68 . There is no significant difference in mean HDL Cholesterol level in both treatment groups ( $>0.05$ ). The mean HDL Cholesterol level of atorvastatin group is 42.7 and in rosuvastatin group is 44.12 . There is no significant difference in mean LDL Cholesterol level in both treatment groups. ( $p>0.05$ ). the mean LDL Cholesterol level of atorvastatin group is 158.74 and in rosuvastatin group is 146.57 . There is no significant difference in mean Triglyceride level in both treatment groups. ( $>0.05)$. the mean Triglyceride level of atorvastatin group is 287 and in rosuvastatin group is 284.94. There is no significant difference in mean VLDL level in both treatment groups. ( $>0.05$ ). the mean VLDL level of atorvastatin group is 57.4 and in rosuvastatin group is 56.98 .

According to Distribution of Serum lipid profile After treatment in relation to Groups There is significant difference in mean serum cholesterol level in both treatment groups $(\mathrm{p}<0.05)$. the mean serum cholesterol level of atorvastatin group is 193.08 and in rosuvastatin group is 176.5. And according to mean rosuvastatin $20 \mathrm{mg}$ have less serum cholesterol in respect to atorvastatin group after treatment. There is significant difference in mean HDL Cholesterol level in both treatment groups $(\mathrm{p}<0.05)$. The mean HDL Cholesterol level of atorvastatin group is 44.42 and in rosuvastatin group is 46.74. And according to mean rosuvastatin $20 \mathrm{mg}$ have less HDL cholesterol in respect to atorvastatin group after treatment. There is significant difference in mean LDL Cholesterol level in both treatment groups $(\mathrm{p}<0.05)$. The mean LDL Cholesterol level of atorvastatin group is
115.77 and in rosuvastatin group is 98.97. And according to mean rosuvastatin $20 \mathrm{mg}$ have less LDL cholesterol in respect to atorvastatin group after treatment. There is significant difference in mean Triglyceride level in both treatment groups. $(\mathrm{p}<0.05)$. The mean Triglyceride level of atorvastatin group is 164.44 and in rosuvastatin group is 153.92. And according to mean rosuvastatin $20 \mathrm{mg}$ have less Triglycerides in respect to atorvastatin group after treatment. There is significant difference in mean VLDL level in both treatment groups. $(\mathrm{p}<0.05)$. the mean VLDL level of atorvastatin group is 32.88 and in rosuvastatin group is 30.78 . And according to mean rosuvastatin $20 \mathrm{mg}$ have less VLDL in respect to atorvastatin group after treatment

Distribution of Serum lipid profile before treatment according to Gender in Atorvastatin $20 \mathrm{mg}$ shows no significant difference in mean serum cholesterol level in both gender $(p>0.05)$. The mean serum cholesterol level of male is 255.85 and in female is 262.63. There is significant difference in mean HDL Cholesterol level in both genders $(p<0.05)$. The mean HDL Cholesterol level of male is 41.17 and in female is 44.63. And according to mean male have less HDL cholesterol in respect to female before treatment. There is no significant difference in mean serum cholesterol level in both gender $(p>0.05)$. the mean serum cholesterol level of male is 156.88 and in female is 161.1 . There is no significant difference in mean serum cholesterol level in both gender $(p>0.05)$. the mean serum cholesterol level of male is 288.96 and in female is 284.5. There is no significant difference in mean serum cholesterol level in both gender ( $p>0.05)$. the mean serum cholesterol level of male is 57.79 and in female is 56.9 .

According to Distribution of Serum lipid profile After treatment according to Gender in Atorvastatin $20 \mathrm{mg}$ There is no significant difference in mean serum cholesterol level in both gender ( $p>0.05)$. the mean serum cholesterol level of male is 190.92 and in female is 195.81.There is significant difference in mean HDL Cholesterol 
level in both genders $(\mathrm{p}<0.05)$. The mean HDL Cholesterol level of male is $\mathbf{4 2 . 9 6}$ and in female is 46.27. And according to mean male have less HDL cholesterol in respect to female before treatment. There is no significant difference in mean serum cholesterol level in both gender $(p>0.05)$. the mean serum cholesterol level of male is 115.12 and in female is 116.6. There is no significant difference in mean serum cholesterol level in both gender $(p>0.05)$. the mean serum cholesterol level of male is 164.21 and in female is 164.72. There is no significant difference in mean serum cholesterol level in both gender ( $>>0.05)$. the mean serum cholesterol level of male is 32.84 and in female is 32.94 .

Distribution of Serum lipid profile before and after treatment in Atorvastatin 20mg shows significant difference in before and after treatment mean serum cholesterol level $(\mathrm{p}<0.05)$. and according to mean serum cholesterol level is reduced in after treatment in atorvastatin group. There is significant difference in before and after treatment mean HDL cholesterol level $(\mathrm{p}<0.05)$. and according to mean HDL cholesterol level is increased in after treatment in atorvastatin group.There is significant difference in before and after treatment mean LDL cholesterol Level $(\mathrm{p}<0.05)$. and according to mean LDL cholesterol level is reduced in after treatment in atorvastatin group. There is significant difference in before and after treatment mean Triglyceride level $(\mathrm{p}<0.05)$. and according to mean Triglyceride level is reduced in after treatment in atorvastatin group.There is significant difference in before and after treatment mean VLDL level $(\mathrm{p}<0.05)$. and according to mean VLDL level is reduced in after treatment in atorvastatin group.

Distribution of Serum lipid profile before treatment according to Gender in Rosuvastatin shows no significant difference in mean serum cholesterol level in both gender $(p>0.05)$. the mean serum cholesterol level of male is 244.83 and in female is 252.31. There is no significant difference in mean HDL Cholesterol level in both genders $(p>0.05)$. The mean HDL Cholesterol level of male is 44.32 and in female is 43.78 . There is no significant difference in mean serum cholesterol level in both gender $(p>0.05)$. the mean serum cholesterol level of male is 143.54 and in female is 151.5. There is no significant difference in mean serum cholesterol level in both gender ( $p>0.05)$. the mean serum cholesterol level of male is 284.83 and in female is 285.1.There is no significant difference in mean serum cholesterol level in both gender $(p>0.05)$. the mean serum cholesterol level of male is 56.96 and in female is 57.02 .

Distribution of Serum lipid profile After treatment according to Gender in Rosuvastatin shows no significant difference in mean serum cholesterol level in both gender $(p>0.05)$. the mean serum cholesterol level of male is $\mathbf{1 7 7 . 9 6}$ and in female is 174.1. There is no significant difference in mean HDL Cholesterol level in both genders ( $p>0.05)$. The mean HDL Cholesterol level of male is 46.93 and in female is 46.42 . There is no significant difference in mean serum cholesterol level in both gender $(\mathrm{p}>0.05)$. the mean serum cholesterol level of male is 99.5 and in female is 98.11. There is no significant difference in mean serum cholesterol level in both gender $(p>0.05)$. the mean serum cholesterol level of male is 157.64 and in female is 147.84.There is no significant difference in mean serum cholesterol level in both gender $(p>0.05)$. the mean serum cholesterol level of male is 31.52 and in female is 29.56 .

Distribution of Serum lipid profile before and after treatment in Rosuvastatin shows significant difference in before and after treatment mean serum cholesterol level $(\mathrm{p}<0.05)$. and according to mean serum cholesterol level is reduced in after treatment in atorvastatin group. There is significant difference in before and after treatment mean HDL cholesterol level $(\mathrm{p}<0.05)$. and according to mean HDL cholesterol level is reduced in after treatment in atorvastatin group.There is significant difference in before and after treatment mean LDL cholesterol level $(p<0.05)$. and according to mean LDL cholesterol 
level is reduced in after treatment in atorvastatin group. There is significant difference in before and after treatment mean Triglyceride level $(\mathrm{p}<0.05)$. and according to mean Triglyceride level is reduced in after treatment in atorvastatin group. There is significant difference in before and after treatment mean VLDL level $(\mathrm{p}<0.05)$. and according to mean VLDL level is reduced in after treatment in atorvastatin group.

Percentage changes in biomedical parameters shows no significant difference found in percentage changes (before to after) in serum cholesterol level in both treatment groups ( $p>0.05$ ). and mean changes in atorvastatin group is 24.78 and in rosuvastatin group is 28.29 . There is significant difference found in percentage changes (before to after) in HDL cholesterol level in both treatment groups $(\mathrm{p}<0.05)$. and mean changes in atorvastatin group is -4.09 and in rosuvastatin group is -6.11 . And according to mean HDL cholesterol level is higher in atorvastatin group. There is no significant difference found in percentage changes (before to after) in LDL cholesterol level in both treatment groups ( $p>0.05$ ). and mean changes in atorvastatin group is 25.12 and in rosuvastatin group is 31.2. There is no significant difference found in percentage changes (before to after) in Triglyceride level in both treatment groups ( $p>0.05$ ). and mean changes in atorvastatin group is 42.62 and in rosuvastatin group is 45.5 . There is no significant difference found in percentage changes (before to after) in VLDL level in both treatment groups $(p>0.05)$. and mean changes in atorvastatin group is 27.69 and in rosuvastatin group is 32.45 .

Distribution of SERUM CHOLESTEROL/HDLC before treatment according to Groups shows significant difference in mean serum cholesterol/HDLC level in both treatment groups $(\mathrm{p}<0.05)$. the mean serum cholesterol/HDLC level of atorvastatin group is 6.16 and in rosuvastatin group is 5.66. And according to mean rosuvastatin $20 \mathrm{mg}$ have less serum cholesterol/HDLC in respect to atorvastatin group before treatment.
Distribution of SERUM CHOLESTEROL/HDLC After treatment according to Groups shows significant difference in mean serum cholesterol/ HDLC level in both treatment groups $(\mathrm{p}<0.05)$. the mean serum cholesterol/HDLC level of atorvastatin group is 4.40 and in rosuvastatin group is 3.81. And according to mean rosuvastatin $20 \mathrm{mg}$ have less serum cholesterol/HDLC in respect to atorvastatin group after treatment.

Distribution of SERUM CHOLESTEROL/HDLC before and after treatment in Atorvastatin 20mg shows significant difference in mean serum cholesterol /HDLC level $(\mathrm{p}<0.05)$. and according to mean serum cholesterol/HDLC level is reduced in after treatment in atorvastatin group.

Distribution of SERUM CHOLESTEROL/HDLC before and after treatment in Rosuvastatin shows significant difference in mean serum cholesterol /HDLC level $(\mathrm{p}<0.05)$. and according to mean serum cholesterol/HDLC level is reduced in after treatment in Rosuvastatin group.

Table 17 There is no significant difference found in percentage changes (before to after) in LDL/HDL level in both treatment groups $(p>0.05)$. and mean changes in atorvastatin group is 27.98 and in rosuvastatin group is 35.26 .

Distribution of LDL/HDL before \& after treatment according to Groups shows significant difference in mean serum LDL/HDL level in both treatment groups $(\mathrm{p}<0.05)$. the mean LDL/HDLC level of atorvastatin group is 3.79 and in rosuvastatin group is 3.36. And according to mean rosuvastatin $20 \mathrm{mg}$ have less serum LDL/HDLC in respect to atorvastatin group before treatment. There is significant difference in mean serum LDL/HDL level in both treatment groups $(p<0.05)$. the mean LDL/HDLC level of atorvastatin group is 2.65 and in rosuvastatin group is 2.15 . And according to mean rosuvastatin $20 \mathrm{mg}$ have less serum LDL/HDLC in respect to atorvastatin group after treatment.

There is significant difference in before and after treatment mean LDL /HDLC level $(\mathrm{p}<0.05)$. and according to mean LDL/HDLC level is reduced in after treatment in Atorvastatin 20mg group. 


\section{JMSCR Vol||06||Issue ||07||Page 288-297||July}

There is significant difference in before and after treatment mean LDL /HDLC level $(\mathrm{p}<0.05)$. and according to mean LDL/HDLC level is reduced in after treatment in Rosuvastatin group.

Atorvastatin and Rosuvastatin significantly decreased Total cholesterol, Triglycerides, LDL$\mathrm{C}$, VLDL-C. There is significant difference in mean HDL Cholesterol level in both treatment groups $(\mathrm{p}<0.05)$.

And according to mean rosuvastatin $20 \mathrm{mg}$ have less LDL cholesterol in respect to atorvastatin group after treatment

There is significant difference found in percentage changes (before to after) in HDL cholesterol level in both treatment groups $(\mathrm{p}<0.05)$. and mean changes in atorvastatin group is -4.09 and in rosuvastatin group is -6.11 . And according to mean HDL cholesterol level is higher in atorvastatin group

There is significant difference in mean serum cholesterol/HDLC level in both treatment groups $(\mathrm{p}<0.05)$. the mean serum cholesterol/HDLC level of atorvastatin group is 4.40 and in rosuvastatin group is 3.81. And according to mean rosuvastatin $20 \mathrm{mg}$ have less serum cholesterol/HDLC in respect to atorvastatin group after treatment.

Table: Distribution of age according to Groups

Group Statistics

\begin{tabular}{|cc|c|c|c|c|c|}
\hline \multicolumn{2}{|c|}{ Group } & $\mathrm{N}$ & Mean & Std. Deviation & T value & P value \\
\hline \multirow{2}{*}{ Age } & Atorvastatin 20mg & 50 & 60.4200 & 13.09633 & 0.287 & 0.775 \\
& Rosuvastatin & 50 & 59.7600 & 9.64166 & & \\
\hline
\end{tabular}

Table : Distribution of Gender according to Groups

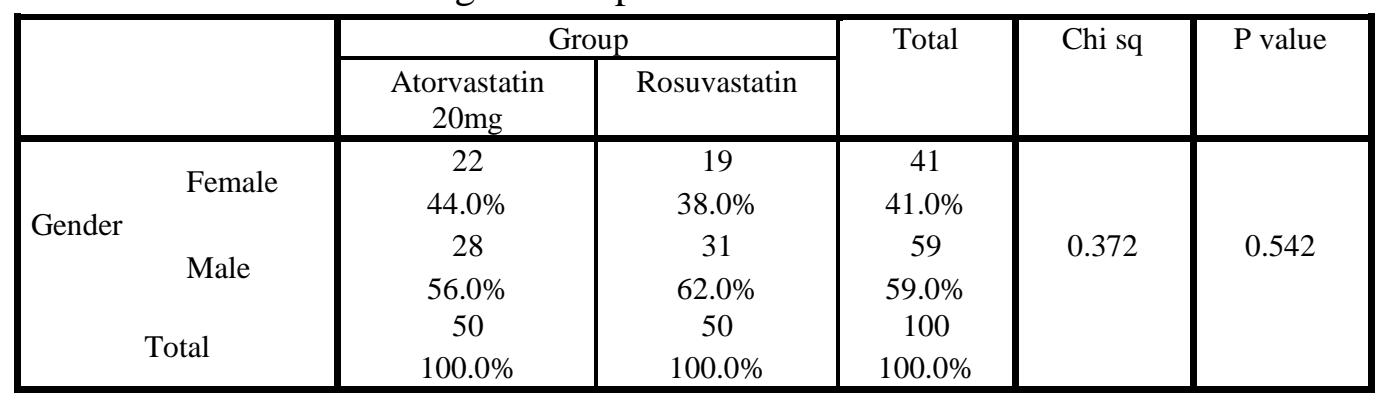

Table : Distribution of BLOOD GLUCOSE according to Groups

Group Statistics

\begin{tabular}{|cc|c|c|c|c|c|}
\hline & Group & $\mathrm{N}$ & Mean & Std. Deviation & T value & P value \\
\hline \multirow{2}{*}{ BLOOD GLUCOSE } & Atorvastatin 20mg & 50 & 258.8400 & 40.19613 & & \\
& Rosuvastatin & 50 & 275.3200 & 52.88510 & 1.754 & 0.083 \\
\hline
\end{tabular}

Table : Distribution of Serum lipid profile before treatment according to Groups

\begin{tabular}{|c|c|c|c|c|c|c|}
\hline & Group & $\mathrm{N}$ & Mean & Std. Deviation & T value & $\mathrm{P}$ value \\
\hline \multirow{2}{*}{ SERUM CHOLESTEROL BEFORE } & Atorvastatin $20 \mathrm{mg}$ & 50 & 258.8400 & 36.61569 & & \\
\hline & Rosuvastatin & 50 & 247.6800 & 30.58974 & 1.654 & 0.101 \\
\hline \multirow{2}{*}{ HDL CHOLESTEROL BEFORE } & Atorvastatin $20 \mathrm{mg}$ & 50 & 42.7000 & 5.70803 & & \\
\hline & Rosuvastatin & 50 & 44.1200 & 4.56535 & 1.374 & 0.173 \\
\hline \multirow{2}{*}{ LDL CHOLESTEROL BEFORE } & Atorvastatin $20 \mathrm{mg}$ & 50 & 158.7400 & 34.65643 & & \\
\hline & Rosuvastatin & 50 & 146.5720 & 26.79735 & 1.964 & 0.052 \\
\hline \multirow{2}{*}{ TRIGLYCERIDES BEFORE } & Atorvastatin $20 \mathrm{mg}$ & 50 & 287.0000 & 21.84267 & & \\
\hline & Rosuvastatin & 50 & 284.9400 & 36.78643 & 0.340 & 0.734 \\
\hline \multirow{2}{*}{ VLDL BEFORE } & Atorvastatin $20 \mathrm{mg}$ & 50 & 57.4000 & 4.36853 & & \\
\hline & Rosuvastatin & 50 & 56.9880 & 7.35729 & 0.340 & 0.734 \\
\hline
\end{tabular}


Table : Distribution of Serum lipid profile After treatment according to Groups

\begin{tabular}{|c|c|c|c|c|c|c|}
\hline & Group & $\mathrm{N}$ & Mean & Std. Deviation & T value & $P$ value \\
\hline \multirow{2}{*}{ SERUM CHOLESTEROL AFTER } & Atorvastatin $20 \mathrm{mg}$ & 50 & 193.0800 & 27.53094 & & \\
\hline & Rosuvastatin & 50 & 176.5000 & 30.40089 & 2.858 & $0.005^{*}$ \\
\hline \multirow{2}{*}{ HDL CHOLESTEROL AFTER } & Atorvastatin $20 \mathrm{mg}$ & 50 & 44.4200 & 5.76439 & & \\
\hline & Rosuvastatin & 50 & 46.7400 & 4.26093 & 2.289 & $0.024 *$ \\
\hline \multirow{2}{*}{ LDL CHOLESTEROL AFTER } & Atorvastatin $20 \mathrm{mg}$ & 50 & 115.7720 & 23.33745 & & \\
\hline & Rosuvastatin & 50 & 98.9760 & 30.73748 & 3.077 & $0.003^{*}$ \\
\hline \multirow{2}{*}{ TRIGLYCERIDES AFTER } & Atorvastatin $20 \mathrm{mg}$ & 50 & 164.4400 & 25.54081 & & \\
\hline & Rosuvastatin & 50 & 153.9200 & 20.18975 & 2.285 & 0.024 \\
\hline \multirow{2}{*}{ VLDL AFTER } & Atorvastatin $20 \mathrm{mg}$ & 50 & 32.8880 & 5.10816 & & \\
\hline & Rosuvastatin & 50 & 30.7840 & 4.03795 & 2.285 & 0.024 \\
\hline
\end{tabular}

\section{Atorvastatin $20 \mathrm{mg}$}

Table : Distribution of Serum lipid profile before treatment according to Gender in Atorvastatin 20mg

\begin{tabular}{|c|c|c|c|c|c|c|}
\hline & Gender & $\mathrm{N}$ & Mean & Std. Deviation & $\mathrm{T}$ value & $P$ value \\
\hline \multirow{2}{*}{ SERUM CHOLESTEROL BEFORE } & Male & 28 & 255.8571 & 37.75036 & & \\
\hline & Female & 22 & 262.6364 & 35.62442 & 0.646 & 0.521 \\
\hline \multirow{2}{*}{ HDL CHOLESTEROL BEFORE } & Male & 28 & 41.1786 & 5.57145 & & \\
\hline & Female & 22 & 44.6364 & 5.39440 & 2.209 & $0.032 *$ \\
\hline \multirow{2}{*}{ LDL CHOLESTEROL BEFORE } & Male & 28 & 156.8857 & 35.18116 & & \\
\hline & Female & 22 & 161.1000 & 34.65150 & 0.423 & 0.674 \\
\hline \multirow{2}{*}{ TRIGLYCERIDES BEFORE } & Male & 28 & 288.9643 & 23.96832 & & \\
\hline & Female & 22 & 284.5000 & 19.05068 & 0.714 & 0.479 \\
\hline \multirow{2}{*}{ VLDL BEFORE } & Male & 28 & 57.7929 & 4.79366 & & \\
\hline & Female & 22 & 56.9000 & 3.81014 & 0.714 & 0.479 \\
\hline
\end{tabular}

Table : Distribution of Serum lipid profile After treatment according to Gender in Atorvastatin 20mg Group Statistics

\begin{tabular}{|c|c|c|c|c|c|c|}
\hline & Gender & $\mathrm{N}$ & Mean & Std. Deviation & $\mathrm{T}$ value & $\mathrm{P}$ value \\
\hline \multirow{2}{*}{$\begin{array}{l}\text { SERUM } \\
\text { AFTER }\end{array}$} & Male & 28 & 190.9286 & 25.74077 & & \\
\hline & Female & 22 & 195.8182 & 30.04384 & 0.619 & 0.539 \\
\hline \multirow{2}{*}{ HDL CHOLESTEROL AFTER } & Male & 28 & 42.9643 & 5.82130 & & \\
\hline & Female & 22 & 46.2727 & 5.24796 & 2.082 & $0.043 *$ \\
\hline \multirow{2}{*}{ LDL CHOLESTEROL AFTER } & Male & 28 & 115.1214 & 22.65610 & & \\
\hline & Female & 22 & 116.6000 & 24.68969 & 0.220 & 0.827 \\
\hline \multirow{2}{*}{ TRIGLYCERIDES AFTER } & Male & 28 & 164.2143 & 24.26300 & & \\
\hline & Female & 22 & 164.7273 & 27.65981 & 0.070 & 0.945 \\
\hline \multirow{2}{*}{ VLDL AFTER } & Male & 28 & 32.8429 & 4.85260 & & \\
\hline & Female & 22 & 32.9455 & 5.53196 & 0.070 & 0.945 \\
\hline
\end{tabular}

Table : Distribution of Serum lipid profile before and after treatment in Atorvastatin 20mg

\begin{tabular}{|l|c|c|c|c|c|}
\hline & Mean & $\mathrm{N}$ & Std. Deviation & T value & P value \\
\hline SERUM CHOLESTEROL BEFORE & 258.8400 & 50 & 36.61569 & & \\
SERUM CHOLESTEROL AFTER & 193.0800 & 50 & 27.53094 & 15.054 & $<0.0001^{*}$ \\
\hline HDL CHOLESTEROL BEFORE & 42.7000 & 50 & 5.70803 & & \\
HDL CHOLESTEROL AFTER & 44.4200 & 50 & 5.76439 & 15.031 & $<0.0001^{*}$ \\
\hline LDL CHOLESTEROL BEFORE & 158.7400 & 50 & 34.65643 & & \\
LDL CHOLESTEROL AFTER & 115.7720 & 50 & 23.33745 & 9.604 & $<0.0001^{*}$ \\
\hline TRIGLYCERIDES BEFORE & 287.0000 & 50 & 21.84267 & & \\
TRIGLYCERIDES AFTER & 164.4400 & 50 & 25.54081 & 31.612 & $<0.0001^{*}$ \\
\hline VLDL BEFORE & 57.4000 & 50 & 4.36853 & & \\
VLDL AFTER & 32.8880 & 50 & 5.10816 & 31.612 & $<0.0001^{*}$ \\
\hline
\end{tabular}




\section{Rosuvastatin}

Table : Distribution of Serum lipid profile before treatment according to Gender in Rosuvastatin Group Statistics

\begin{tabular}{|c|c|c|c|c|c|c|}
\hline & Gender & $\mathrm{N}$ & Mean & Std. Deviation & T value & $P$ value \\
\hline \multirow{2}{*}{ SERUM CHOLESTEROL BEFORE } & Male & 31 & 244.8387 & 30.43145 & & \\
\hline & Female & 19 & 252.3158 & 31.10029 & 0.836 & 0.407 \\
\hline \multirow{2}{*}{ HDL CHOLESTEROL BEFORE } & Male & 31 & 44.3226 & 4.98924 & & \\
\hline & Female & 19 & 43.7895 & 3.88128 & 0.397 & 0.693 \\
\hline \multirow{2}{*}{ LDL CHOLESTEROL BEFORE } & Male & 31 & 143.5484 & 27.31563 & & \\
\hline & Female & 19 & 151.5053 & 25.88078 & 1.020 & 0.313 \\
\hline \multirow{2}{*}{ TRIGLYCERIDES BEFORE } & Male & 31 & 284.8387 & 35.28937 & & \\
\hline & Female & 19 & 285.1053 & 40.10250 & 0.025 & 0.980 \\
\hline \multirow{2}{*}{ VLDL BEFORE } & Male & 31 & 56.9677 & 7.05787 & & \\
\hline & Female & 19 & 57.0211 & 8.02050 & 0.025 & 0.980 \\
\hline
\end{tabular}

Table : Distribution of Serum lipid profile After treatment according to Gender in Rosuvastatin Group Statistics

\begin{tabular}{|c|c|c|c|c|c|c|}
\hline & Gender & $\mathrm{N}$ & Mean & Std. Deviation & T value & $P$ value \\
\hline \multirow{2}{*}{$\begin{array}{l}\text { SERUM CHOLESTEROL } \\
\text { AFTER }\end{array}$} & Male & 31 & 177.9677 & 33.15568 & & \\
\hline & Female & 19 & 174.1053 & 25.96128 & 0.432 & 0.667 \\
\hline \multirow{2}{*}{ HDL CHOLESTEROL AFTER } & Male & 31 & 46.9355 & 4.57483 & & \\
\hline & Female & 19 & 46.4211 & 3.79057 & 0.411 & 0.683 \\
\hline \multirow{2}{*}{ LDL CHOLESTEROL AFTER } & Male & 31 & 99.5032 & 33.58916 & & \\
\hline & Female & 19 & 98.1158 & 26.27338 & 0.153 & 0.879 \\
\hline \multirow{2}{*}{ TRIGLYCERIDES AFTER } & Male & 31 & 157.6452 & 17.09103 & & \\
\hline & Female & 19 & 147.8421 & 23.66259 & 1.698 & 0.096 \\
\hline \multirow{2}{*}{ VLDL AFTER } & Male & 31 & 31.5290 & 3.41821 & & \\
\hline & Female & 19 & 29.5684 & 4.73252 & 1.698 & 0.096 \\
\hline
\end{tabular}

Table : Distribution of Serum lipid profile before and after treatment in Rosuvastatin

\begin{tabular}{|l|c|c|c|c|c|}
\hline & Mean & $\mathrm{N}$ & Std. Deviation & T value & P value \\
\hline SERUM CHOLESTEROL BEFORE & 247.6800 & 50 & 30.58974 & & \\
SERUM CHOLESTEROL AFTER & 176.5000 & 50 & 30.40089 & 16.096 & $<0.0001^{*}$ \\
\hline HDL CHOLESTEROL BEFORE & 44.1200 & 50 & 4.56535 & & \\
HDL CHOLESTEROL AFTER & 46.7400 & 50 & 4.26093 & 13.687 & $<0.0001^{*}$ \\
\hline LDL CHOLESTEROL BEFORE & 146.5720 & 50 & 26.79735 & & \\
LDL CHOLESTEROL AFTER & 98.9760 & 50 & 30.73748 & 11.290 & $<0.0001^{*}$ \\
\hline TRIGLYCERIDES BEFORE & 284.9400 & 50 & 36.78643 & & \\
TRIGLYCERIDES AFTER & 153.9200 & 50 & 20.18975 & 26.746 & $<0.0001^{*}$ \\
\hline VLDL BEFORE & 56.9880 & 50 & 7.35729 & & \\
VLDL AFTER & 30.7840 & 50 & 4.03795 & 26.746 & $<0.0001^{*}$ \\
\hline
\end{tabular}

\section{References}

1. Anderson KM, Odell PM, Wilson PW, Kannel WB. Cardiovascular risk profiles. Am Heart J 1991;121:293-8.

2. Athyros VG, Papageorgiou AA, Hatzikonstandinou HA, Didangelos TP, Carina MV, Kranitsas DF et al. Safety and efficacy of long-term statin-fibrate combinations in patients with refractory familial combined hyperlipidemia. Am J Cardiol. 1997;80(5):608-13.

3. Bakker-Arkema RG, Davidson $\mathrm{MH}$, Goldstein RJ, Davignon J, Isaacsohn JL, Weiss SR et al. Efficacy and safety of a new
HMG-CoA reductase inhibitor, atorvastatin, in patients with hypertriglyc-eridemia. JAMA. 1996;275(2):128-33.

4. Bhopal Raj, Unwin N, White M, White M, Yallop J, Walker L, et al. Heterogeneity of coronary heart disease risk factors in Indian, Pakistani, Bangladeshi, and European origin populations: cross sectional study. Biomed Journal. 1999;319(7204):215-20.

5. Brewer HB Jr. New features of the National Cholesterol Education Program Adult Treatment Panel III lipid-lowering guidelines. Clin Cardiol. 2003;26(S3):19-24. 
6. Brunzell JD, Failor RA. Diagnosis and Treatment of dyslipidemia. In: Dale DC, Federman DD. ACP MEDICINE, 3rd ed. New York: WebMD Inc; 2007. P. 729-47.

7. Cannon CP, Braunwald E, McCabe $\mathrm{CH}$, et al. Intensive versus moderate lipid lowering with statins after acute coronary syndromes. N Engl J Med 2004; 350:1495-1501.

8. Ellen RL, McPherson R. Long-term efficacy and safety of fenofibrate and a statin in the treatment of combined hyperlipidemia. Am J Cardiol. 1998;81(4): 60-65B.

9. Farnier M, Picard S. Diabetes: Statins, fibrates, or both. Curr Atheroscler Rep. 2001;3(1):19-28.

10. Fiévet C, Staels B. Combination therapy of statins and fibrates in the management of cardiovascular risk. Current Opinion in Lipidology. 2009;20(6):505-11.

11. Fleg JL, Mete M, Howard BV, Umans JG, Roman MJ, Ratner RE, et al. Effect of statins alone versus statins plus ezetimibe on carotid atherosclerosis in type 2 diabetes: The SANDS (Stop Atherosclerosis in Native Diabetics Study) trial. J Am Coll Cardiol 2008;52:2198-205.

12. Guerin M, Lassel TS, Le Goff W, Farnier M, Chapman MJ. Action of atorvastatin in combined hyperlipidemia: Preferential reduction of cholesteryl ester transfer from HDL to VLDL1 particles. Arterioscler Thromb Vasc Biol. 2000;20(1):189-97.

13. Haffner SM. Management of dyslipidemia in adults with diabetes. Diabetes Care. 2002;251:74-7.

14. Josan K, Majundar SR, Mcalister FA. The efficacy and safety of intensive statin therapy: A meta analysis randomized trials. CMAJ 2008;176:576-83.

15. Kinlay S, Schwartz GG, Olsson AG, Rifai N, Leslie SJ, Sasiela WJ, et al. High dose atorvastatin enhances the decline in inflammatory markers in patients with acute coronary syndromes.

Circulation 2003;26:571-81

16. Kiortisis DN, Millionis H, Bairaktari E, Elisaf MS. Efficacy of combination of atorvastatin and micronized fenofibrate in the treatment of severe mixed hyperlipidemia. Eur J Clin Pharmacol. 2000;56(9-10):631-35.

17. Kumar T, Kapoor A. Premature coronary artery disease in North Indians: An angiography study of 1971 patients. Indian Heart J 2005;57:311-8.

18. McKenney JM, Jones PH, Adamczyk MA, Cain VA, Bryzinski BS,BlasettoJW et al. Comparison of the efficacy of rosuvastatin versus atorvastatin, simvastatin, and pravastatin in achieving lipid goals: results from the STELLAR trial. Curr Med Res Opin. 2003;19(8):689-98.

19. National Cholesterol Education Program (NCEP) Expert Panel on Detection, Evaluation, and Treatment of High Blood Cholesterol in Adults (Adult Treatment Panal III). Final report. Circulation. 2002;106(25):3143-421.

20. Ravi GR, Pradeepa R, Mohan V. Hyperlipidemia and coronary artery disease. An Update. Indian Heart J 2004;56:21-6.

21. Talbert RL. Dyslipidemia. In: Diprio JT, editor. Pharmacotherapy-A Pathophysiological Approach. 8th ed. New York: McGraw-Hill; 2008. p. 365-88.

22. Vega GL, Ma PT, Cater NB, Filipchuk N, Meguro S, Garcia AB et al. Effects of adding fenofibrate (200 $\mathrm{mg} /$ day) to simvastatin (10 $\mathrm{mg} /$ day) in patients withcombined hyperlipidemia and metabolic syndrome. Am J Cardiol. 2003;91(8): 956-60.

23. Wierzbicki AS, Lumb PJ, Semra Y, Chik G, Christ ER, Crook MA. Atorvastatin compared with simvastatin based therapies in the management of severe familial hyperlipidemia. QJM 1999;92:387-94. 